\title{
A Quick Classification Method of the Power Quality Disturbances
}

\author{
Yi Tang1, Hao Liu1,2 \\ ${ }^{1}$ School of Information and Electrical Engineering, China University of Mining \& Technology, Xuzhou, China \\ ${ }^{2}$ NARI Group Corporation (State Grid Electric Power Research Institute), Nanjing, China \\ Email: tangyi@cumt.edu.cn, ditfft@126.com
}

Received 3 November 2013; revised 5 April 2014; accepted 20 April 2014

Copyright $(2014$ by authors and Scientific Research Publishing Inc.

This work is licensed under the Creative Commons Attribution International License (CC BY).

http://creativecommons.org/licenses/by/4.0/

c) (i) Open Access

\begin{abstract}
This paper introduces a quick classification method of the power quality disturbances. Based on analyzing the characteristics of different electrical disturbance signals in time domain, four distinctive features are extracted from electrical signals for classifying different power quality disturbances and then an automatic classifier is proposed. Using the proposed classification method, a PQ monitor of the classifying power quality disturbances is developed based on the TMS320F2812 DSP micro-processor. Semi-physical simulation, lab experiment and field measurement results have verified that this proposed method can classify single or complex disturbance signals effectively.
\end{abstract}

\section{Keywords}

Power Quality, Disturbance Classification, Noise

\section{Introduction}

To detect and improve power quality, we first need to monitor and analyze the power quality disturbances. There have been many methods presented, such as Fourier transform [1], wavelet transform [2]-[4], S transform and so on. The Fourier transform is suitable to analyze stationary signals, and has a good effect on stationary disturbance like harmonics; the wavelet transform has advantage of analyzing singularity and nonstationary signals [5] [6]; $\mathbf{S}$ transform is the inheritance and development of short-time Fourier transform and wavelet transform. So it has the advantages of the both [7]-[11]. And it analyzes signal features more comprehensively and it has been a hot research tool of power quality disturbance classification. They are all the time frequency transform methods. This paper presents a method based on the time domain analysis of the power quality disturbance signals and it has some advantages compared to the time frequency transform methods. It will be discussed in details in Section 4. 


\section{The Analysis of Power Quality Disturbances in Time Domain}

The general single-phase voltage signal can be expressed as the superposition of the fundamental wave voltage and the disturbance signals:

$$
u(t)=\sqrt{2} U_{1} \sin \left(\omega t+\varphi_{1}\right)+\sqrt{2} \sum_{h=2}^{n} U_{h} \sin \left(h \omega t+\varphi_{h}\right)+\sum_{s=1}^{m} \sqrt{2} U_{s} \sin \left(\omega_{s} t+\varphi_{s}\right) \mathrm{e}^{-\gamma_{s}\left(t-t_{s}\right)} 1\left(t-t_{s}\right)
$$

where $U_{1}$ is the RMS (root mean square) voltage with the system fundamental frequency; $\omega$ is the system fundamental angular frequency; $\varphi_{1}$ is the initial phase angle; $U_{h}$ is the $h_{\text {th }}$ harmonic RMS voltage; $\varphi_{h}$ is the $h_{\text {th }}$ harmonic initial phase angle; $\omega_{s}$ is the angular frequency between harmonic waveforms and not an integer multiple of the system fundamental frequency, for example, the frequencies of interharmonics and oscillatory transients; $U_{s}$ is the $\omega_{s}$ RMS voltage with $\omega_{s}$ angular frequency; $\varphi_{s}$ is the initial phase angle of the $\omega_{s}$ angular frequency voltage; $\gamma_{s}$ is the oscillatory transient attenuation constant. When $\gamma_{s}=0, U_{s}$ is the interharmonic RMS voltage and when $\gamma_{s} \neq 0, U_{s}$ is the oscillatory transients RMS voltage; $t_{s}$ is the starting time; $l(t)$ is the unit step function. Table 1 shows that characteristics of the disturbances which IEEE classified [12]. All the simulation parameters in this paper are chosen from Table 1 randomly.

In Equation (1), when $U_{1}$ is stationary, equal to the rating value and

$$
\sqrt{2} \sum_{h=2}^{n} U_{h} \sin \left(h \omega t+\varphi_{h}\right)+\sum_{s=1}^{m} \sqrt{2} U_{s} \sin \left(I_{s} \omega t+\varphi_{s}\right) \mathrm{e}^{-\gamma_{s}\left(t-t_{s}\right)} 1\left(t-t_{s}\right)=0,
$$

Equation (1) represents the ideal voltage. So the voltage disturbance can be divided into two categories. One is the disturbances with the change of the $U_{1}$ amplitude, including voltage sag, swell, interruption, under voltage, over voltage, fluctuation, flicker and so on. The other is the additive disturbances, including harmonics, oscillatory transients, impulse voltage, interharmonics and so on. From the aspect of disturbance duration, we can also divide the disturbances into two categories. One is stationary disturbance, including voltage fluctuation and flicker, under voltage, over voltage, continuous interruption, harmonics, interharmonics and so on. The other is transient disturbances, including voltage sag, swell, instantaneous interruption, oscillatory transients, impulse voltage and so on. So the power quality disturbances can be divided into four categories by time domain features, shown in Table 2.

For voltage sag, swell and interruption has the similar characteristics, the author only takes voltage sag as the analyzing object. The other two can also be identified by the method presented in this paper.

If $u(t)$ in Equation (1) is multiplied by $\sqrt{2} \sin \left(\omega t+\varphi_{1}\right)$, we can get:

$$
u(t) * \sqrt{2} \sin \left(\omega t+\varphi_{1}\right)=u_{1 d}+u_{1 i}(t)+u_{1 u n}(t)
$$

\begin{tabular}{cccc}
\multicolumn{2}{l}{ Table 1. Typical characteristics of power system disturbances. } \\
\hline Disturbances & Typical spectral content & Typical duration & Typical voltage magnitude \\
\hline Voltage sag & & 0.5 cycles - 1 min & $0.1-0.9 \mathrm{pu}$ \\
Fluctuation and flicker & $<25 \mathrm{~Hz}$ & Intermittent & $0.1 \%-7 \%$ \\
Harmonics & $0-100^{\text {th }} \mathrm{Hz}$ & Steady state & $0 \%-20 \%$ \\
Oscillatory transients & $<5 \mathrm{kHz}$ & $0.3-50 \mathrm{~ms}$ & $0-4 \mathrm{pu}$ \\
Interharmonics & $0-6 \mathrm{kHz}$ & Steady state & $0 \%-2 \%$ \\
\hline
\end{tabular}

Table 2. The categories of the voltage disturbance.

\begin{tabular}{ccc}
\hline Voltage amplitude disturbances & Stationary & Fluctuation and flicker, under voltage ,over voltage \\
& Transient & Voltage sag, swell, transient interruption \\
\hline Additive disturbances & Stationary & Harmonics, interharmonics \\
& Transient & Oscillatory transients, impulse voltage \\
\hline
\end{tabular}




$$
\begin{aligned}
& \text { where, } u_{1 d}=U_{1}-U_{1} \cos \left(2 \omega t+2 \varphi_{1}\right) \text {, and } U_{1 d}=\int_{0}^{T} u_{1 d} \mathrm{~d} t=U_{1} \\
& u_{1 i}=U_{1} \cos \left(2 \omega t+2 \varphi_{1}\right)+\sum_{h=2}^{N} U_{h}\left\{\cos \left[(h-1) \omega t+\varphi_{h}-\varphi_{1}\right]-\cos \left[(h+1) \omega t+\varphi_{h}+\varphi_{1}\right]\right\} \text {, and } U_{1 i}=\int_{0}^{T} u_{1 i} \mathrm{~d} t=0 \\
& u_{1 u n}=\sum_{s=1}^{m} U_{s}\left\{\cos \left[\left(I_{s} \omega-\omega\right) t+\varphi_{s}-\varphi_{1}\right]-\cos \left[\left(I_{s} \omega+\omega\right) t+\varphi_{s}+\varphi_{1}\right]\right\} \mathrm{e}^{-\gamma_{s}\left(t-t_{s}\right)} 1\left(t-t_{s}\right) \text {, and } U_{1 u n}=\int_{0}^{T} u_{1 u n} \mathrm{~d} t \neq 0
\end{aligned}
$$

Equation (2) consists of three parts. First is DC component $u_{1 d}$. Second is an AC component $u_{1 i}$ with an integer multiple system frequency. Third is an AC component $u_{1 u n}$ with a non-integer multiple system frequency. After a full cycle (0 - T) integral of the (2) we can see that $U_{1 i}=0$, and some AC components still exist in $U_{1 u n}$. Figure 1 is the curve of the full cycle integral of (2). In Figure 1(a) and Figure 1(b) only contain $U_{1 d}$. Figure 1(c) contains $U_{1 d}$ and $U_{1 i}\left(U_{1 i}=0\right)$. Figure $1(\mathrm{~d})$ and Figure 1(e) contain $U_{1 d}$ and $U_{1 u n}$. For $u_{1 u n}$ is the sine wave AC value of non-integer multiple system frequency, after a full cycle integral $U_{1 u n} \neq 0$. It shows the existence of the sine wave AC disturbance of non-integer multiple system frequency. The simulation parameters of the following pictures are chosen in the range of Table 1.

The square of Equation (1) is:

$$
u(t) * u(t)=u_{d}+u_{i}+u_{u n}
$$

The expanded formula of (3) is long, but also is consists of three parts: DC component $u_{d}$, an AC component $u_{1 i}$ with an integer multiple system frequency, an AC component $u_{1 u n}$ with a non-integer multiple system frequency. In it:

$$
U_{d}=\int_{0}^{T} u_{d} \mathrm{~d} t=U_{1}^{2}(t)+\sum_{h=2}^{N} U_{h}^{2}+\sum_{s=1}^{m} U_{s}^{2} \mathrm{e}^{-2 \gamma_{s}\left(t-t_{s}\right)} 1\left(t-t_{s}\right)
$$

The curve of a full cycle integral of (3) is shown in Figure 2.

By comparing Figure 1 and Figure 2, we can find that Figure 1(a) and Figure 1(b) are the same with Figure 2(a) and Figure 2(b) because there is no additive disturbance in the voltage sag and fluctuation and flicker. The harmonics is additive disturbance, so the $U_{d} / U_{N}$ in Figure 2(c) is larger than $U_{1} / U_{N}$ in Figure 1 (c). And the difference between them is the amplitude of the additive disturbance $\sqrt{\sum_{h=2}^{N} U_{h}^{2}}$. The oscillatory transients and interharmonics are the additive disturbances. So the $U_{d} / U_{N}$ in Figure 2(d) and Figure 2(e) is larger than the $U_{1} / U_{N}$ in Figure 1(d) and Figure 1(e). And the difference is also the amplitude of additive disturbance $\sqrt{\sum_{s=1}^{m} U_{s}^{2} \mathrm{e}^{-2 \gamma_{s}\left(t-t_{s}\right)} 1\left(t-t_{s}\right)}$.

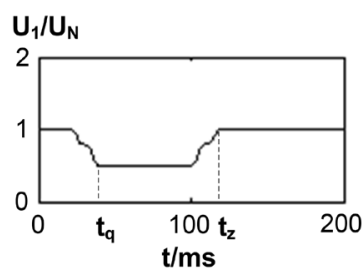

(a)

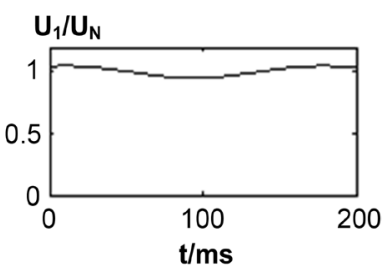

(b)

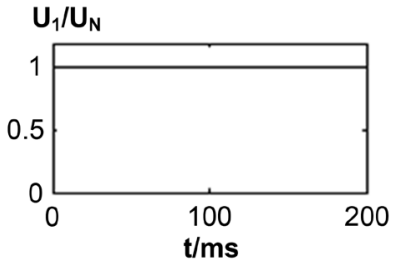

(c)

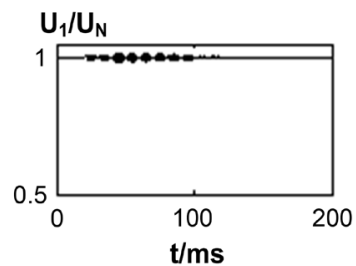

(d)

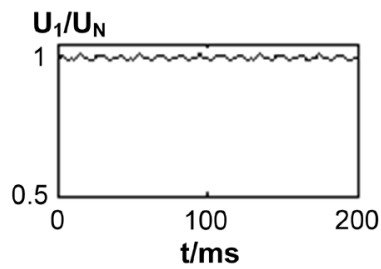

(e)

Figure 1. The curve of full cycle integral of (2). (a) Voltage sag; (b) fluctuation and flicker; (c) harmonics; (d) Oscillatory transients; (e) Interharmonics. 


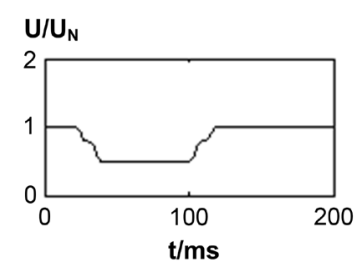

(a)

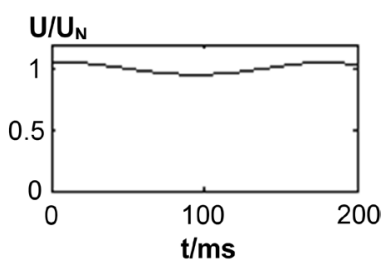

(b)

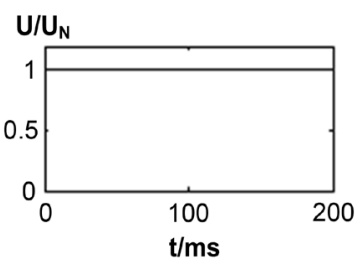

(c)

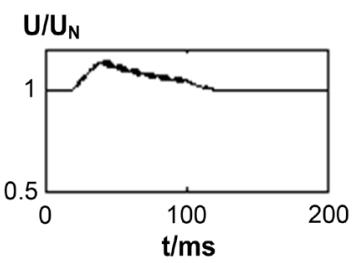

(d)

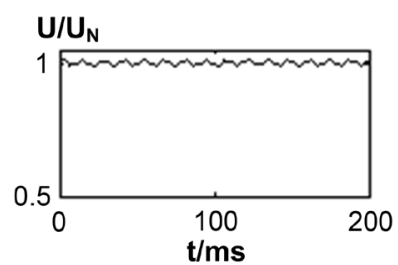

(e)

Figure 2. The curve of full cycle integral of (3). (a) Voltage sag; (b) Fluctuation and flicker; (c) Harmonics; (d) Oscillatory transients; (e) Interharmonics.

\section{Basic Idea of the Classification of the Power Quality Disturbances}

Though above analysis, some individual features of the power quality disturbance singles can be shown in timedomain:

1) Equation (2) has the effect of selecting system fundamental frequency. The DC component, which can be gotten by low pass filter from Equation (2), is the RMS voltage with system fundamental frequency, which is not affected by additive disturbance. And its change is equivalent to the amplitude disturbance of the RMS voltage (like voltage sag, swell, transient interrupt, under voltage, over voltage, continuous interrupt, fluctuation, flicker and so on).

2) The DC component of Equation (3) is the geometric sum of the RMS voltage with system fundamental frequency and all other additive disturbance RMS voltages. So the geometric difference of the Equation (3) and Equation (2)'s DC component is exactly equivalent to the amplitude of the additive disturbance (like harmonics, oscillatory transients, impulse voltage and interharmonics).

3) Figure 1(d) and Figure 1(e)'s curves contain $U_{1 d}$ and $U_{1 u n}$. The component $U_{\text {1un }}$ exists usually because of the existence of the interharmonics and the oscillatory transients which are non-integer system fundamental frequency sine wave signal. $U_{1 u n} \neq 0$ indicates the existence of the interharmonics or oscillatory transients.

So, the next 4 features $\left(F_{1}-F_{4}\right)$ can be used to classify power quality single disturbances and the mixed disturbances can be considered as the "superposition" of the single disturbances. The calculating flow chart of the 4 features is shown in Figure 3.

1) $F_{1}=U_{1}^{\prime} / U_{N}$ is taken as a feature after Equation (2) is filtered by a low pass. Because of the (2)'s effect of frequency selection, $F_{1}$ is the system fundamental wave voltage amplitude variation value which is not affected by additive disturbance. It reflects the extent of the fundamental wave amplitude change. So the information of system fundamental RMS voltage change can be known from the extent of the $F_{1}$ change. Then it can be used to identify whether there are the voltage sag, swell, instantaneous interruption, under voltage, over voltage, continuous interruption, fluctuation and flicker in electrical singles (shown in Table 3).

2) $F_{2}=\frac{100}{N} \sum_{k=1}^{N} \sqrt{\left[U^{2}(k)-U_{1}^{2}(k)\right] / U_{1}^{2}(k)} \cdot N$ is the total sample points during the analysis period of time $\tau$ (for $F_{2}$ is used to detect stationary additive disturbances, the analysis period of time can be enlarged. This paper takes $\tau=2 \mathrm{~s}, 100$ cycles). $F_{2}$ is the RMS value of the additive disturbance during the analysis period of time $\tau$. If $F_{2}>0$, the additive disturbance must exist. If $F_{2}$ is stationary, the disturbance must be harmonics and $F_{2}$ is equivalent to THD. $F_{2}>1.5$ can be the threshold value of the harmonics and interharmonics.

3) If $F_{2}>0, \quad F_{3}=\frac{100}{N} \sum_{k=1}^{N}\left|U_{1}(k)-U_{1}(k-1)\right|$ means the average increment of the $U_{1 u n}$. It can be used to classify the additive disturbances harmonics and interharmonics. If interharmonics exist in Equation (2), the curve of $U_{1 u n}$ will contain AC component of non-integer system fundamental frequency (shown in Figure 1(c) 


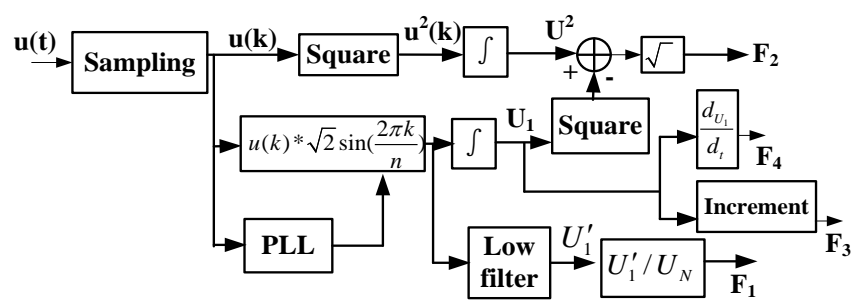

Figure 3. The flow chart of calculating classification features.

Table 3. Amplitude change disturbance classifications with $F_{1}$.

\begin{tabular}{cc}
\hline c & $F_{1}=1.1-1.2$ pu, duration $>1$ min \\
Under voltage & $F_{1}=0.8-0.9$ pu, duration $>1$ min \\
Voltage interruption & $F_{1}<0.1 \mathrm{pu}$, duration: $10 \mathrm{~ms}-3$ s instantaneous interruption; \\
$3-60$ s temporary interruption; $>60$ s power off \\
Voltage sag \\
$F_{1}=0.1-0.9 \mathrm{pu}$, duration $10 \mathrm{~ms}-1 \mathrm{~min}$ \\
Voltage swell \\
$F_{1}=1.1-1.8 \mathrm{pu}$, duration $10 \mathrm{~ms}-1 \mathrm{~min}$ \\
Fluctuation and flicker & $F_{1}$ is voltage fluctuation in $0.9-1.1$ pu randomly \\
\hline
\end{tabular}

and Figure 1(e)). Then value of $F_{3}$ is much larger than that when only harmonics exist. The MATLAB simulation shows that when $F_{3} \geq 1$, interharmonics exist; when $F_{3} / F_{2} \geq 0.5$, only interharmonics exist; when $F_{3} / F_{2}<0.5$, both harmonics and interharmonics exist.

4) $F_{4}=\operatorname{Max}\left\{\left|U_{1}(k)-U_{1}(k-1)\right|\right\}-F_{3} . F_{4}$ is the maximum differential value of $U_{1 u n}$. The characteristic that the amplitude of instantaneous disturbance changes fast determines $F_{4}$ a large number. But to stationary disturbance, $F_{4}$ is small or even zero. The value of $F_{4}$ can determine the instantaneous disturbances exist or not. The MATLAB simulation shows that the threshold can be 15 . If $F_{4}>15$, the instantaneous disturbance exists; if $F_{4}<15$, no instantaneous disturbance exists. For instance, when $F_{1}$ shows amplitude disturbance exists, if $F_{4}>15$, the disturbance should be instantaneous amplitude disturbance such as the voltage sag, swell, instantaneous interruption, and if $F_{4}<15$, the disturbance should be stationary amplitude disturbance such as under voltage, over voltage, fluctuation and flicker and when $F_{1}$ shows no amplitude disturbance exists, if $F_{4}>15$, the disturbance must be the additive instantaneous disturbance such as oscillatory transient.

Table 4 shows the simulation value of 5 single disturbances and 4 mixed disturbances. Figure 4 is the flow chart of the automate classification of the disturbances.

Disturbances can be classified into two categories: voltage amplitude disturbance and additive disturbance as shown in Table 2. $F_{1}$ is used to identify whether voltage amplitude disturbances exist, and $F_{2}$ is used to identify whether additive disturbances exist. $F_{3}$ is used to identify whether (there is interharmonics in additive disturbances) interharmonics exist when $F_{2}>1.5$. In the disturbances classification, it is very hard to identify the circumstance that both harmonics and interharmonics exist. The interharmonics have effect on $F_{2}$ and $F_{3}$. When the interharmonic disturbance is heavy, $F_{3}$ is large, and $F_{2}$ is large, too. So $F_{3} / F_{2}$ is relatively steady. When harmonics and interharmonics both exist, $F_{3} / F_{2}$ is smaller than that when only interharmonics exist. A lot of simulation results indicate that $F_{3} / F_{2}$ can identify the circumstance that both harmonics and interharmonics exist correctly. $F_{4}$ is used to identify whether transient disturbances exist.

\section{Discussion}

Comparing with the other power quality disturbance classification methods using some kinds of transforms, the method presented by this paper has advantages as follows:

1) The single disturbance can be identified by one feature or the combination of some features. That means if one feature or some features satisfied some conditions, a disturbance or mixed disturbances can be sure. Then the disturbance classification will not be probable, but be definitive and the correct rate of the disturbance classification would be very high. And it makes the classification simpler. For example, as shown in Figure 4, if 


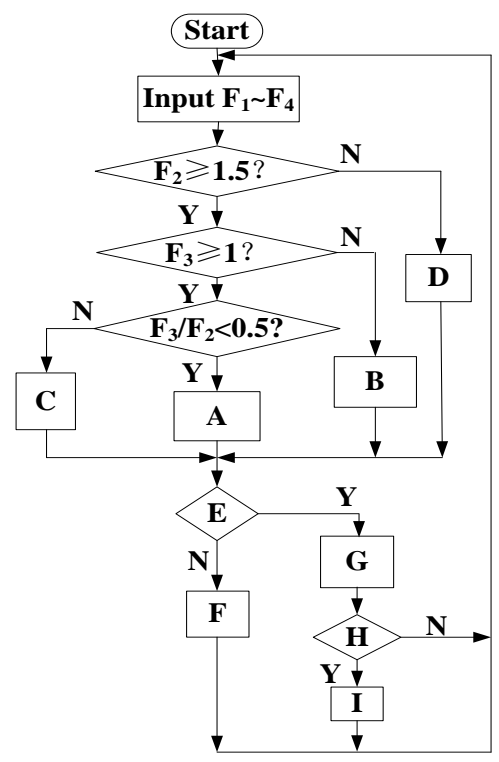

Figure 4. The flow chart of the automate classification. A: Harmonics + Interharmonics; B: Harmonics; C: Interharmonics; D: No stationary additive disturbance; $\mathrm{E}: F_{1}=$ Constant $\approx 1 \mathrm{pu}$ ?; F: Identify the amplitude disturbances by $F_{1}$; G: No amplitude disturbance; $\mathrm{H}: F_{4}>15$ ?; I: Osillatory transients.

Table 4. The simulation value of the features.

\begin{tabular}{|c|c|c|c|c|}
\hline The disturbances & The disturbance parameters & $F_{2}$ & $F_{3}$ & $F_{4}$ \\
\hline Fluctuation and flicker & Amplitude: 0.95 - 1.05 & 0.68 & 0.91 & 1.96 \\
\hline Voltage sag & Sag amplitude: $0.5 \mathrm{pu}$ & 0.49 & 0.40 & 38.66 \\
\hline Harmonics & ${ }^{*} 5^{\text {th }} 4 \% ; 7^{\text {th }} 3 \%$ & 5.0 & 0 & 0 \\
\hline Oscillatory transients & $M_{s}=0.8 \mathrm{pu}, f_{s}=1025 \mathrm{~Hz} ; U_{s}=0.1$ & 0.49 & 0.22 & 59.95 \\
\hline Interharmonics & $f=125 \mathrm{~Hz}$, amplitude $2 \%$ & 1.99 & 1.27 & 1.78 \\
\hline Voltage sag and harmonics & $0.5 \mathrm{pu}, 5^{\text {th }} 4 \% ; 7^{\text {th }} 3 \%$ & 5.41 & 0.40 & 39.45 \\
\hline Fluctuation and harmonics & Amplitude: $0.95-1.05 ; 5^{\text {th }} 4 \% ; 7^{\text {th }} 3 \%$ & 5.05 & 0.91 & 1.31 \\
\hline Harmonics and oscillatory transients & $5^{\text {th }} 4 \% ; 7^{\text {th }} 3 \%, \gamma_{s}=0.1, U_{s}=0.8 \mathrm{pu}, f_{s}=1025 \mathrm{~Hz}$ & 5.34 & 0.22 & 59.92 \\
\hline Harmonics and interharmonics & $5^{\text {th }} 4 \% ; 7^{\text {th }} 3 \% ; f_{s}=125 \mathrm{~Hz}, U_{s}=2 \%$ & 5.37 & 1.27 & 1.73 \\
\hline
\end{tabular}

$F_{2} \geq 1.5$ and $F_{3}<1$, only harmonics exist; if $F_{2} \geq 1.5, \quad F_{3} \geq 1$ and $F_{3} / F_{2} \geq 0.5$, only interharmonics exist; if $F_{2} \geq 1.5, F_{3} \geq 1$ and $F_{3} / F_{2}<0.5$, both harmonics and interharmonics exist.

2) The features extracted from one disturbance won't change a lot for the existence of the other disturbance. This is shown clearly in Table 4. For example, when the voltage sag and harmonics both exist, $F_{1}$ which is used to identify voltage sag won't change for the existence of harmonics. And $F_{2}$ (only harmonics exist, $F_{2}=5.0$ ), which is used to identify harmonics changes a little by the existence of voltage sag (harmonics + voltage sag, $F_{2}=5.41$ ). When the oscillatory transients exist in harmonics, $F_{2}$ increases a little (from 5.0 to 5.23). The harmonics and interharmonics are both additive disturbances, so $F_{2}$ is the approximate geometric summation of their amplitude $\left(\sqrt{4^{2}+3^{2}+2^{2}}=5.39\right.$, the simulation result in Table 4 is 5.37). For another example, $F_{4}$ which is used to identify transient voltage sag $\left(F_{4}=38.66\right)$ and oscillatory transients $\left(F_{4}=59.95\right)$ will not change a lot for the existence of harmonics (voltage sag + harmonics, $F_{4}=39.45$; oscillotary + har- 
monics, $F_{4}=59.92$ ). This characteristic of the features is the key of the classifying the mixed disturbances. For the idea of this paper considers the mixed disturbances as the "superposition" of the single disturbances. For the characteristics above, all single or mixed disturbances can be classified correctly by simple classifying program, and the classifying results won't conflict and are definitive.

3) The classifying features have clear physical meanings. So it profits the evaluation of the power quality disturbance. The physical meaning of $F_{1}$ is the per unit value of the system fundamental RMS voltage, so the amplitude of all the voltage amplitude disturbances can be gained from $F_{1}$. And the starting time $t_{q}$ and the ending time $t_{z}$ of the transient amplitude disturbance can also be gained from $F_{1}$ (shown in Figure 1). The physical meaning of $F_{2}$ is the content of the additive disturbances. So $F_{2}$ gives the content of the harmonics and interharmonics accurately. The oscillatory amplitude and the attenuation constant of the oscillatory transients can be gained by fitted method from Figure 2(d).

4) The calculating time is much less, and profits to be used in real-time power quality disturbance classification.

5) The features extracted are low-pass filtered or the full cycle integral values, so it has good ability of noise proof.

\section{Verifications}

Using the proposed power quality disturbance classification method, a PQ monitor is developed based on the TMS320F2812 DSP micro-processor. Semi-physical simulation, lab experiment and field measurement results have verified the proposed method.

\subsection{Semi-Physical Simulation Results}

The authors use D space semi-physical experiment platform as the disturbance signal generator. The PQ monitor samples the signals generated by D space, identifies disturbances and evaluates their parameters. Table 5 shows that it identifies the disturbance types correctly and evaluates their parameters accurately.

\begin{tabular}{|c|c|c|c|}
\hline The disturbance type & $\begin{array}{l}\text { The experiments } \\
\text { times }\end{array}$ & $\begin{array}{l}\text { The correct ratio of } \\
\text { identifying the } \\
\text { disturbance type }\end{array}$ & $\begin{array}{l}\text { The average error of the } \\
\text { parameters evaluation }\end{array}$ \\
\hline The voltage sag & 100 & $100 \%$ & $2.12 \%$ \\
\hline The fluctuation and flicker & 100 & $99 \%$ & $3.01 \%$ \\
\hline The harmonics & 100 & $98 \%$ & $2.00 \%$ \\
\hline The oscillatory transients & 100 & $98 \%$ & $2.45 \%$ \\
\hline The interharmonics & 100 & $97 \%$ & $6.33 \%$ \\
\hline The harmonics + The voltage sag & 100 & $100 \%$ & $3.58 \%$ \\
\hline The harmonics + The fluctuation and flicker & 100 & $96 \%$ & $2.99 \%$ \\
\hline The harmonics + The oscillatory transients & 100 & $100 \%$ & $3.07 \%$ \\
\hline The fluctuation and flicker + The voltage sag & 100 & $100 \%$ & $4.28 \%$ \\
\hline The fluctuation and flicker + The oscillatory transients & 100 & $100 \%$ & $4.14 \%$ \\
\hline The interharmonics + The voltage sag & 100 & $100 \%$ & $2.78 \%$ \\
\hline The interharmonics + The oscillatory transients & 100 & $99 \%$ & $2.99 \%$ \\
\hline The interharmonics + The fluctuation and flicker & 100 & $96 \%$ & $3.46 \%$ \\
\hline The interharmonics + The harmonics & 100 & $97 \%$ & $2.53 \%$ \\
\hline The interharmonics + The harmonics + The voltage sag & 100 & $99 \%$ & $4.01 \%$ \\
\hline $\begin{array}{l}\text { The interharmonics + The harmonics + } \\
\text { The voltage sag + The fluctuation and flicker }\end{array}$ & 100 & $98 \%$ & $3.98 \%$ \\
\hline
\end{tabular}


The authors give three types of disturbances: the voltage sag, the voltage sag plus harmonics, the fluctuation plus harmonics plus interharmonics plus voltage sag to present 5 single disturbances and 11 mixed disturbances.

1) The voltage sag

In the following tables the same symbols have the same meanings.

Table 6 doesn't give the true or false results because the PQ monitor gives the correct results every time. Table 6 shows that the PQ monitor can evaluate the voltage sag parameter very well. The relative error is a little big when the voltage sag amplitude is close to the voltage sag threshold value, but the absolute error is not big.

2) The voltage sag plus harmonics

The authors do not show the identifying results in Table 7, for all harmonics plus voltage sag are identified by the PQ monitor correctly. Table 7 shows that the superposed disturbance doesn't make the features change a lot, which means the features $F_{2}$ and $F_{3}$ are relatively independent. The identifying results and the parameters evaluation are not affected by the superposition of the disturbances.

3) The fluctuation plus harmonics plus interharmonics plus voltage sag

Table 8 shows that the addition of the fluctuation and flicker affects the feature $F_{2}$ a little, but doesn't affect the feature $F_{3}$. The big amount of harmonics may blanket the existence of interharmonics, because the identifying term of the harmonics plus interharmonics is $F_{3} / F_{2}>0.5$.

\subsection{Lab Experiment Results}

A lab experiment circuit is shown as Figure 5. When the switch $S$ is turned on, there is voltage sag on $R_{1}$. The voltage signal $u_{1}$ is sampled by the PQ monitor and the oscilloscope.

$U=380 \mathrm{~V}, R_{1}=1 \mathrm{k} \Omega, R_{2}=2 \mathrm{k} \Omega, R_{3}=3.9 \Omega$. $S$ is an AC contact. FU is a fuse. When $S$ is turned on and the current of the FU branch is large enough, the FU will blowing out and the branch will be cut off. Then there will be a voltage sag in $u_{1}$ as shown in Figure 5(b).

The experiment results shown in Table 9 indicate that the PQ monitor can identify disturbances correctly and evaluate the voltage sag lasting time and amplitude accurately.

Table 6. The experiments results of voltage sag.

\begin{tabular}{cccccc}
\hline$t_{m}(\mathrm{~ms})$ & $t_{s}(\mathrm{~ms})$ & $e_{t}$ & $a_{m}(\mathrm{pu})$ & $a_{s}(\mathrm{pu})$ & $e_{a}$ \\
\hline 35 & 40 & 5 & 0.112 & 0.1 & 0.012 \\
53 & 60 & 7 & 0.211 & 0.2 & 0.011 \\
77 & 80 & 3 & 0.305 & 0.3 & 0.005 \\
98 & 100 & 2 & 0.360 & 0.35 & 0.01 \\
116 & 120 & 4 & 0.389 & 0.40 & 0.011 \\
138 & 140 & 2 & 0.447 & 0.45 & 0.003 \\
\hline
\end{tabular}

$t_{m}$ : The voltage sag lasting time measured by the PQ monitor; $t_{s}$ : The setting time of the voltage sag lasting time; $e_{t}$ : The error between time 1 and time $2 ; a_{m}$ : The voltage sag amplitude measured by the PQ monitor; $a_{s}$ : The setting amplitude of voltage sag amplitude; $e_{a}$ : The error between amplitude 1 and amplitude 2 .

Table 7. The experiments results of harmonics plus voltage sag.

\begin{tabular}{cccccccc}
\hline THD & $e_{\mathrm{THD}}$ & $t_{m}(\mathrm{~ms})$ & $e_{\mathrm{t}}$ & $a_{m}(\mathrm{pu})$ & $e_{a}$ & $F_{2}$ & $F_{3}$ \\
\hline $2.08 \%$ & 0.0018 & 38 & 3.52 & 0.102 & 0.011 & 2.08 & 0.04 \\
$3.12 \%$ & 0.0029 & 54 & 4.76 & 0.212 & 0.011 & 3.12 & 0.01 \\
$4.09 \%$ & 0.0014 & 78 & 2.60 & 0.307 & 0.005 & 4.09 & 0.02 \\
$5.06 \%$ & 0.0010 & 98 & 1.93 & 0.361 & 0.010 & 5.06 & 0.13 \\
$5.97 \%$ & 0.0019 & 115 & 4.77 & 0.387 & 0.010 & 5.97 & 0.05 \\
\hline
\end{tabular}

$e_{\mathrm{THD}}$ : The error between the measured THD by PQ monitor and the setting THD. 
Table 8. The experiments results of voltage fluctuation plus harmonics plus interharmonics plus voltage sag.

\begin{tabular}{|c|c|c|c|c|}
\hline The disturbance parameters & $F_{2}$ & $F_{3}$ & Results & Remarks \\
\hline $\begin{array}{l}\text { Fluctuation modulating wave amplitude } 0.02 \text {, frequency } \\
6 \mathrm{~Hz} \text {; interharmonics content } 2 \% \text {,frequency } 125 \mathrm{~Hz} \text {; } \\
\text { harmonics THD } 2 \% \text {; voltage sag amplitude } 0.4 \mathrm{pu}\end{array}$ & 4.72 & 3.75 & $\begin{array}{l}\text { Voltage Fluctuation plus } \\
\text { harmonics plus interharmonics } \\
\text { plus voltage sag }\end{array}$ & \\
\hline $\begin{array}{l}\text { Fluctuation modulating wave amplitude } 0.03 \text {, frequency } \\
8 \mathrm{~Hz} \text {; interharmonics content } 2 \% \text {,frequency } 125 \mathrm{~Hz} \text {; } \\
\text { harmonics THD } 2 \% \text {; voltage sag amplitude } 0.4 \mathrm{pu}\end{array}$ & 4.80 & 3.80 & $\begin{array}{l}\text { Voltage fluctuation plus } \\
\text { harmonics plus interharmonics } \\
\text { plus voltage sag }\end{array}$ & \\
\hline $\begin{array}{l}\text { Fluctuation modulating wave amplitude } 0.02 \text {, frequency } \\
6 \mathrm{~Hz} \text {; interharmonics content } 2 \% \text {,frequency } 125 \mathrm{~Hz} \text {; } \\
\text { harmonics THD } 2 \% \text {; voltage sag amplitude } 0.4 \mathrm{pu}\end{array}$ & 4.91 & 3.82 & $\begin{array}{l}\text { Voltage fluctuation plus } \\
\text { harmonics plus interharmonics } \\
\text { plus voltage sag }\end{array}$ & \\
\hline $\begin{array}{l}\text { Fluctuation modulating wave amplitude } 0.05 \text {, frequency } \\
6 \mathrm{~Hz} \text {; interharmonics content } 2 \% \text {,frequency } 125 \mathrm{~Hz} \text {; } \\
\text { harmonics THD } 2 \% \text {; voltage sag amplitude } 0.4 \mathrm{pu}\end{array}$ & 4.98 & 3.80 & $\begin{array}{l}\text { Voltage fluctuation plus } \\
\text { harmonics plus interharmonics } \\
\text { plus voltage sag }\end{array}$ & \\
\hline $\begin{array}{l}\text { Fluctuation modulating wave amplitude } 0.02 \text {, frequency } \\
6 \mathrm{~Hz} \text {; interharmonics content } 1 \% \text {,frequency } 125 \mathrm{~Hz} \text {; } \\
\text { harmonics THD } 2 \% \text {; voltage sag amplitude } 0.4 \mathrm{pu}\end{array}$ & 3.12 & 1.07 & $\begin{array}{l}\text { Voltage fluctuation plus } \\
\text { harmonics plus voltage sag }\end{array}$ & $\begin{array}{l}\text { When the interharmonics } \\
\text { content is lower than } 1 \% \text {, } \\
\text { and the harmonics content is } \\
\text { large, the error is a little large }\end{array}$ \\
\hline $\begin{array}{l}\text { Fluctuation modulating wave amplitude } 0.02 \text {, frequency } \\
6 \mathrm{~Hz} \text {; interharmonics content } 2 \% \text {,frequency } 1245 \mathrm{~Hz} \text {; } \\
\text { harmonics THD } 2 \% \text {; voltage sag amplitude } 0.4 \mathrm{pu}\end{array}$ & 4.21 & 3.68 & $\begin{array}{l}\text { Voltage fluctuation plus } \\
\text { harmonics plus interharmonics } \\
\text { plus voltage sag }\end{array}$ & \\
\hline $\begin{array}{l}\text { Fluctuation modulating wave amplitude } 0.02 \text {, frequency } \\
6 \mathrm{~Hz} \text {; interharmonics content } 2 \% \text {,frequency } 125 \mathrm{~Hz} \text {; } \\
\text { harmonics THD } 3 \% \text {; voltage sag amplitude } 0.4 \mathrm{pu}\end{array}$ & 5.25 & 3.71 & $\begin{array}{l}\text { Voltage fluctuation plus } \\
\text { harmonics plus interharmonics } \\
\text { plus voltage sag }\end{array}$ & \\
\hline $\begin{array}{l}\text { Fluctuation modulating wave amplitude } 0.02 \text {, frequency } \\
6 \mathrm{~Hz} \text {; interharmonics content } 2 \% \text {,frequency } 125 \mathrm{~Hz} \text {; } \\
\text { harmonics THD 5\%; voltage sag amplitude } 0.5 \mathrm{pu}\end{array}$ & 7.27 & 3.75 & $\begin{array}{l}\text { Voltage fluctuation plus } \\
\text { harmonics plus interharmonics } \\
\text { plus voltage sag }\end{array}$ & \\
\hline $\begin{array}{l}\text { Fluctuation modulating wave amplitude } 0.02 \text {, frequency } \\
6 \mathrm{~Hz} \text {; interharmonics content } 2 \% \text {,frequency } 125 \mathrm{~Hz} \text {; } \\
\text { harmonics THD } 2 \% \text {; voltage sag amplitude } 0.7 \mathrm{pu}\end{array}$ & 4.05 & 3.69 & $\begin{array}{l}\text { Voltage fluctuation plus } \\
\text { harmonics plus interharmonics } \\
\text { plus voltage sag }\end{array}$ & \\
\hline $\begin{array}{l}\text { Fluctuation modulating wave amplitude } 0.02 \text {, frequency } \\
6 \mathrm{~Hz} \text {; interharmonics content } 2 \% \text {,frequency } 125 \mathrm{~Hz} \text {; } \\
\text { harmonics THD } 2 \% \text {; voltage sag amplitude } 0.8 \mathrm{pu}\end{array}$ & 4.11 & 3.70 & $\begin{array}{l}\text { Voltage fluctuation plus } \\
\text { harmonics plus interharmonics } \\
\text { plus voltage sag }\end{array}$ & \\
\hline
\end{tabular}

Table 9. The voltage sag experiments results comparison table.

\begin{tabular}{ccccccc}
\hline Identifying results & $t_{m}(\mathrm{~ms})$ & $t_{\text {om }}(\mathrm{ms})$ & $e_{t}$ & $a_{m}(\mathrm{pu})$ & $a_{\text {om }}(\mathrm{pu})$ & $e_{a}$ \\
\hline Voltage sag & 100 & 102 & 2 & 0.842 & 0.854 & 0.012 \\
Voltage sag & 102 & 105 & 3 & 0.838 & 0.833 & 0.005 \\
Voltage sag & 101 & 103 & 2 & 0.857 & 0.872 & 0.015 \\
Voltage sag & 108 & 110 & 2 & 0.813 & 0.801 & 0.012 \\
Voltage sag & 113 & 114 & 1 & 0.839 & 0.825 & 0.014 \\
\hline
\end{tabular}

a: Error means the difference between values evaluated by PQ monitor and ones measured by the oscilloscope. For the oscilloscope measured value has error itself, but here, no error is considered. The meaning of error in the other tables is the same.

\subsection{Field Measurement Results}

A PQ monitor is equipped to a steel pipe factory substation to monitor the harmonics disturbance and the oscillatory transient disturbances. The results are shown in Table 10 and Table 11.

The field monitoring results in Table 10 show that the PQ monitor identifies harmonics correctly and evaluates the THD accurately.

To catch the oscillatory transients, a PQ monitor is equipped to Shi-Qiao substation. The oscillatory transient signals are generated by switching three phase capacitors. The three phase voltage waveform is shown as Figure 6. 


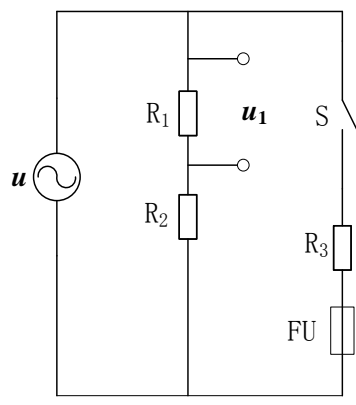

(a)

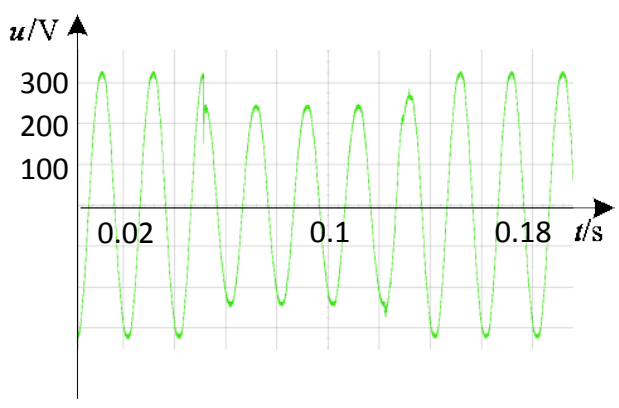

(b)

Figure 5. The voltage sag experiment. (a) The voltage sag experiment circuit; (b) The waveform of $u_{1}$.

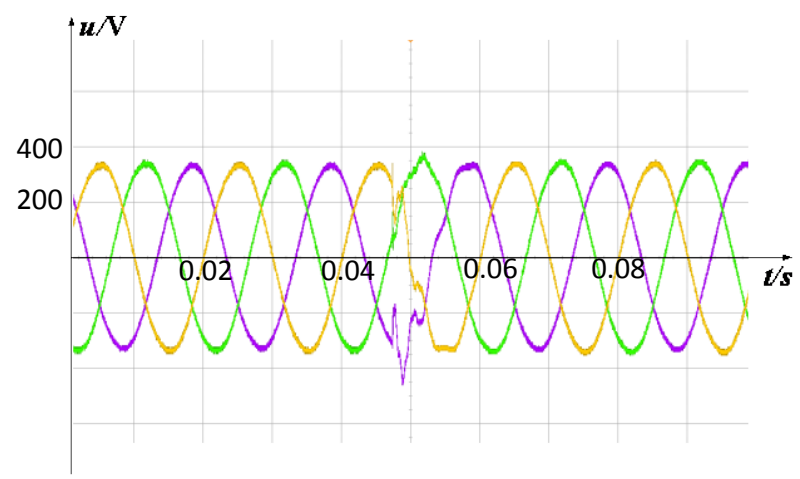

Figure 6. The three phase voltage waveform of capacitors switching in Shi-Qiao substation.

Table 10. The harmonics experiments results comparison table.

\begin{tabular}{cccc}
\hline Identifying results & $\mathrm{THD}_{m}$ & $\mathrm{THD}_{\text {om }}$ & Error \\
\hline Harmonics & $4.2 \%$ & $4.4 \%$ & 0.0020 \\
Harmonics & $5.0 \%$ & $5.2 \%$ & 0.0020 \\
Harmonics & $4.8 \%$ & $5.0 \%$ & 0.0020 \\
Harmonics & $4.5 \%$ & $4.8 \%$ & 0.0030 \\
Harmonics & $5.7 \%$ & $6 \%$ & 0.0030 \\
\hline
\end{tabular}

$\mathrm{THD}_{m}$ : THD measured by the PQ monitor; $\mathrm{THD}_{o m}$ : THD measured by the oscilloscope.

Table 11. The experiments results of oscillatory transient in Shi-Qiao substation.

\begin{tabular}{ccccccc}
\hline Identifying results & $t_{m}(\mathrm{~ms})$ & $t_{\text {om }}(\mathrm{ms})$ & Error & $a_{m}(\mathrm{pu})$ & $a_{\text {om }}(\mathrm{pu})$ & Error \\
\hline Oscillatory transients & 12.43 & 12.56 & 0.13 & 0.70 & 0.78 & 0.08 \\
Oscillatory transients & 13.56 & 13.63 & 0.070 & 0.75 & 0.82 & 0.07 \\
Oscillatory transients & 14.28 & 14.39 & 0.11 & 0.78 & 0.79 & 0.01 \\
Oscillatory transients & 12.85 & 12.98 & 0.13 & 0.74 & 0.85 & 0.11 \\
Oscillatory transients & 14.50 & 14.01 & 0.49 & 0.88 & 0.93 & 0.05 \\
\hline
\end{tabular}

$t_{o m}$ : The oscillatory transients lasting time measured by the oscilloscope; $a_{\text {om }}$ : The oscillatory transients amplitude measured by the oscilloscope. 
The author takes one phase wave to analyze (the purple one). The field experiment results are shown in Table 11.

Table 11 shows that the PQ monitor identifies the oscillatory transients correctly and evaluates their parameters accurately. The difference between the values evaluated by the PQ monitor and ones measured by oscilloscope is small.

\section{Conclusion}

Comparing with analyzing power quality disturbance signals in frequency domain, the method presented by this paper has some advantages. First, if one feature or some features satisfied some conditions, a disturbance or mixed disturbances can be sure. That is to say, the disturbance classification would not be probable, but be definitive. Second, the features extracted won't change a lot for the existence of the other disturbances. This characteristic is the key of classifying the mixed disturbances. Third, the features have clear physical meanings. So it profits the evaluation of the disturbance parameters.

\section{References}

[1] Heydt, G.T., Fjeld, P.S., Liu, C.C., et al. (1999) Applications of the Window FFT to Electric Power Quality Assessment. IEEE Transactions on Power Delivery, 14, 1411-1416. http://dx.doi.org/10.1109/61.796235

[2] Gaing, Z.-L. (2004) Wavelet-Based Neural Network for Power Disturbance Recognition and Classification. IEEE Transactions on Power Delivery, 19, 1560-1568. http://dx.doi.org/10.1109/TPWRD.2004.835281

[3] Ece, D.G. and Gerek, O.N. (2004) Power Quality Event Detection Using Joint 2-D-Wavelet Subspaces. IEEE Transactions on Instrumentation and Measurements, 53, 1040-1046. http://dx.doi.org/10.1109/TIM.2004.831137

[4] Chilukuri, M.V. and Dash, P.K. (2004) Multiresolution S-Transform-Based Fuzzy Recognition System for Power Quality Events. IEEE Transactions on Power Delivery, 19, 323-330. http://dx.doi.org/10.1109/TPWRD.2003.820180

[5] Gaouda, A.M., Salama, M.M.A., Sultan, M.K. and Chikhani, A.Y. (1999) Power Quality Detection and Classification Using Wavelet-Multiresolution Signal Decomposition. IEEE Transactions on Power Delivery, 14, 1469-1476. http://dx.doi.org/10.1109/61.796242

[6] Santoso, S., Powers, E.J., Grady, W.M. and Hofmann, P. (1996) Power Quality Assessment via Wavelet Transform Analysis. IEEE Transactions on Power Delivery, 11, 924-930. http://dx.doi.org/10.1109/61.489353

[7] Dash, P.K., Panigrahi, B.K. and Panda, G. (2003) Power Quality Analysis Using S-Transform. IEEE Transactions on Power Delivery, 18, 406-411. http://dx.doi.org/10.1109/TPWRD.2003.809616

[8] Stockwell, R.G., Mansinha, L. and Lowe, R.P. (1996) Localization of the Complex Spectrum the S Transform. IEEE Transactions on Signal Processing, 44, 998-1001. http://dx.doi.org/10.1109/78.492555

[9] Axelberg, P.G.V., Gu, I.Y.-H. and Bollen, M.H.J. (2007) Support Vector Machine for Classification of Voltage Disturbances. IEEE Transactions on Power Delivery, 22, 1297-1303. http://dx.doi.org/10.1109/TPWRD.2007.900065

[10] Mishra, S., Bhende, C.N. and Panigrahi, B.K. (2008) Detection and Classification of Power Quality Disturbances Using S-Transform and Probabilistic Neural Network. IEEE Transactions on Power Delivery, 23, 280-287. http://dx.doi.org/10.1109/TPWRD.2007.911125

[11] Zhao, F.Z. and Yang, R.G. (2007) Power-Quality Disturbance Recognition Using S-Transform. IEEE Transactions on Power Delivery, 22, 944-950. http://dx.doi.org/10.1109/TPWRD.2006.881575

[12] IEEE Std 1159-1995 (1995) IEEE Recommended Practice for Monitoring Electric Power Quality. 